\title{
Design of filling self-stressing concrete to use in strengthening of columns by prefabricated jacketing
}

\author{
P. Carballosa*, D. Revuelta, Alfredo Fernández-Escandón \\ Institute for Construction Sciences Eduardo Torroja, CSIC, Serrano Galvache 4, 28033 Madrid, Spain
}

\section{H I G H L I G H T S}

- A design and characterization of an self-stressing SCC is offered.

- An improved alternative for the reinforcement of pillars by confinement is proposed.

- Turning the reinforcement action from passive to active from casting is proved.

- A double-ring test device determine effectively the expansion of the concrete.

- The double-ring device eliminates the dependence of the setting time from ASTM C878.

\section{A R T I C L E I N F O}

\section{Article history:}

Received 14 March 2020

Received in revised form 14 August 2020

Accepted 21 August 2020

Available online 20 September 2020

\section{Keywords:}

Expansive self-compacting concrete

Restrained expansion

Self-Stressing concrete

Mechanical properties

Strengthening

CFRP jacketing

Steel jacketing

CFT columns

\begin{abstract}
A B S T R A C T
This study proposes the design and characterization of an expansive self-compacting concrete (SCC) with self-stressing properties for its use as a filling in reinforcement systems by external prefabricated jacketing. The self-compacting characteristic ensures the correct filling of the inner space and the characteristic of expansiveness (self-stressing) guarantees a correct transmission of tensions from the column to the prefabricated reinforcement jacket. In the design, a K-type expansive agent based on calcium sulfoaluminate is used in the doses of $10 \%$ and $15 \%$ and the influence of its addition on the fresh properties and the compressive strength on the reference mix of SCC is analysed. The restrained expansion is evaluated in prisms by the standard method ASTM C878 and by means of an alternative method based on a double ring device that simulates the configuration of reinforcement systems using carbon fiber reinforced polymers (CFRP) or steel external jacketing. Finally, the efficiency of the proposed strengthening system is compared to that usually used for CFRP jacketing directly glued on the element like concrete specimens and reinforced concrete columns. The results show that the double-ring based test device presents a high degree of correlation with the prism-based standard method and that the proposed strengthening based on filling self-stressing SCC and external prefabricated jacketings is an efficient solution that allows to move from a passive reinforcement system (CFRP jacketing glued directly to the column) to an active one that allows the reinforcement to contribute from the initial moments of the cast-in-place of the self-stressing SCC.
\end{abstract}

(c) 2020 Elsevier Ltd. All rights reserved.

\section{Introduction}

Nowadays, reinforced concrete is the main material used in most civil and building structures. These structures are designed, projected and calculated in such a way that they should withstand the environmental and mechanical actions which they are supposed to sustain throughout their service life with an enough margin of safety.

\footnotetext{
* Corresponding author.

E-mail addresses: carballosa@ietcc.csic.es (P. Carballosa), d.revuelta@ietcc.csic. es (D. Revuelta), alfredofeg@ietcc.csic.es (A. Fernández-Escandón).
}

Occasionally, due to defects in the project or execution, changes in the use of the structure, unexpected increases in load demand, appearance of actions not considered in the calculation, deterioration of materials or manifestation of natural disasters [1], the strength capacity of the structure is compromised in such a way that it exceeds the safety threshold that guarantees its integrity. For this reason, an intervention is often required to retrofit, recover or improve the strength capacity of the structure to ensure safety and/or an adequate response to the new mechanical or environmental actions.

In the last decades, engineers have used different methods for retrofitting, reinforcement or repairing of existing structures. One of the most used techniques for concrete columns is the confine- 
ment of the element [2] by an external jacketing [2]. Numerous laboratory research and field applications have shown that this reinforcement system effectively improves the mechanical properties and durability of the reinforced element [3-7]. One of the limitations, however, is that it is a passive system, i.e. the reinforcement action is not effective until the jacketing is loaded, which happens only when the load exceeds the load bear by the element at the time of the intervention. According to the material and fitting system, four types of external jacketing for columns are most commonly used today:

a) Concrete jacketing poured in-situ, with or without bar reinforcement [8].

b) Prefabricated steel jacketing, bolted or directly attached to the column by pressure [9].

c) Fiber jacketing glued directly to the column, called fiberreinforced polymer (FRP) wrapping [10].

d) Prefabricated steel or fiber jacketing with interposition of a filling concrete or mortar [11].

This last jacketing type is based on the so-called Concrete Filled Tube (CFT) system, where a pipe (usually of steel) is filled with concrete [12]. The CFT system is characterized by its high strength, good ductility and fatigue resistance, so its use extends rapidly, e.g., for the construction of arch bridges [13].

As it has been mentioned before, there are numerous investigations carried out on reinforcement systems considered as a whole [2-11]. However, there are few examples of design and characterization on the materials that infill between the outer jacket and the reinforced column, although one of the main drawbacks that may arise with this reinforcement system is that the conventional concrete or mortar used for filling may experience shrinkage, which prevents the correct transmission of stresses between the reinforced column and the outer jacket, so the effectiveness of the reinforcement can be limited [14].

Shrinkage is an inherent characteristic of concrete. There are several types of shrinkage: chemical, autogenous, thermal, carbonation or drying shrinkage. Drying shrinkage is usually the largest in magnitude. It is a volumetric contraction in the hardened state generated by the evaporation of free water contained in pores and the column pressure generated by this evaporation. If the movement of the element is restricted, the contraction will generate tensile stresses on the material that, if they exceed the relatively low tensile strength of the concrete, will lead to cracks in the element [15].

Since 1960 [16] the use of expansive concrete arise as an alternative to diminish the problems derived from shrinkage. Expansive concrete is the general term used for concrete composed of the usual materials (cement, water, sand, coarse aggregate, and other additives or admixtures) plus a hydraulic expansive cement or agent, unlike conventional portland cement, induces an increase of the concrete volume after setting and during the first ages of hardening. Expansive concretes can be broadly divided into shrinkage compensating concrete and self-stressing concrete when classified according to the magnitude of their expansive capacity [17]. Among the several expansive agents [18] added to the concrete causing a controlled increase in the concrete volume, the most widely used are those based on the formation of ettringite $[19,20]$, according to the following reaction:

$$
\mathrm{C}_{4} \mathrm{~A}_{3}+8 \mathrm{C}+6 \mathrm{C}+96 \mathrm{H} \rightarrow 3 \mathrm{C}_{6} \mathrm{~A}_{3} \mathrm{H}_{32}
$$

Most studies on the phenomena of expansion based on the formation of ettringite have been made on cements [21,22].The number of research on the effects of these expanding agents on concrete, and specifically on self-compacting concrete, is smaller $[23,24]$.
This work offers an improved alternative for the reinforcement of columns by confinement with prefabricated exterior jacketing of carbon fiber reinforced polymers (CFRP) or steel, through the design and characterization of an expansive SCC for filling. The self-compacting characteristic ensures the whole filling of the gap between column and jacket, and the expansion (selfstressing concrete) guarantees the correct transmission of the tensions between the column and the prefabricated reinforcement jacket, as well as the loading of the jacket, from practically the first moment of its application, turning the reinforcement from passive to active from the beginning.

\section{Experimental}

\subsection{Materials and mix proportions}

A reference SCC mix and two additional SCC mixes with dosages of $10 \%$ and $15 \%$ in cement weight of a commercially available a Ktype expansive agent based on calcium sulfoaluminate (fix mixture of lime, ye'elemite and anhydrite) were used. For ensuring the filling ability of the mixes, the silica aggregate maximum size was limited to $8 \mathrm{~mm}$. Table 1 shows the SCC compositions in weight percentage.

The magnitude and rate of the expansion can be conditioned by changes in the concrete raw materials. To guarantee the homogeneity of the mixtures during the mix design and to ensure that the expansion was only conditioned by the added proportion of expansive agent and by the curing conditions $[25,26]$ the origin and nature of the raw materials were not changed.

The components used in these SCC mixtures were a commercial Portland cement CEM I 425R with a specific surface area of $3750 \mathrm{~cm}^{2} / \mathrm{gr}$ and a specific gravity of $315 \mathrm{gr} / \mathrm{cm}^{3}$, a commercial K-type calcium sulfoaluminate expansive agent with a specific surface area of $3700 \mathrm{~cm}^{2} / \mathrm{gr}$ and a specific gravity of $300 \mathrm{gr} / \mathrm{cm}^{3}$, a natural silica aggregate of fraction $0 / 8 \mathrm{~mm}$ with a specific gravity of $2,58 \mathrm{gr} / \mathrm{cm}^{3}$ and a water absorption of $0,1 \%$ both properties determined according to UNE-EN 1097-6 [27] test, a commercial limestone filler with a specific gravity of $2,74 \mathrm{gr} / \mathrm{cm}^{3}$ added in the proportion of $10 \%$ by weight of cement and a polycarboxylate superplasticizer admixture in powder added in the proportion of $0,25 \%$ by weight of cement. The chemical compositions in oxides of the cement and the K-type expansive agent obtained by means of X-ray fluorescence (XRF) are showed in Table 2.

The XRD analysis obtained (Fig. 1) indicate that K-type expansive agent is mainly composed by anhydrite, ye'elemite and lime.

Since mixing time could influence the expansion [21] and with the purpose of avoiding possible localized expansions due to a bad distribution of the expansive agent, a mixing protocol as follows was established: dry components (cement, additions, aggregates and K-type expansive agent) were mixed first for $1 \mathrm{~min}$, and once

Table 1

Nominal SCC compositions in weight percentage for $1 \mathrm{~m}^{3}$.

\begin{tabular}{llll}
\hline Components & SCC-0 & SCC-10 & SCC-15 \\
\hline Water & $10 \%$ & $10 \%$ & $10 \%$ \\
Cement CEM I 425R & $18 \%$ & $18 \%$ & $18 \%$ \\
Silicous Aggregates 0/8 & $70 \%$ & $68 \%$ & $67 \%$ \\
Superplastizer Powder & $0 \%$ & $0 \%$ & $0 \%$ \\
Type K expansive agent & $0 \%$ & $2 \%$ & $3 \%$ \\
Limestone Filler & $2 \%$ & $2 \%$ & $2 \%$ \\
K-type expansive agent (\%) & $0 \%$ & $10 \%$ & $15 \%$ \\
W/C ratio & 0,58 & 0,58 & 0,58 \\
W/B ratio (B = Cement + K-type agent + filler) & 0,53 & 0,48 & 0,46 \\
Paste volume* (\%) & $41,4 \%$ & $42,7 \%$ & $43,4 \%$ \\
\hline
\end{tabular}

*An air content of $5 \%$ was considered. 
Table 2

Elemental chemical composition of the cement and the K-type expansive agent.

\begin{tabular}{|c|c|c|c|c|c|c|c|c|c|c|}
\hline Components & $\mathrm{SiO}_{2}(\%)$ & $\mathrm{Al}_{2} \mathrm{O}_{3}(\%)$ & $\mathrm{Fe}_{2} \mathrm{O}_{3}(\%)$ & MgO (\%) & $\mathrm{SO}_{3}(\%)$ & $\mathrm{CaO}(\%)$ & CaO libre (\%) & $\mathrm{CaO}$ total $(\%)$ & Lost of ignition (\%) & Insoluble residue (\%) \\
\hline Cement CEM I 42,5R & 20,2 & 6 & 2,4 & 1,6 & 3,4 & 63,2 & 1,1 & 64,3 & 2 & 0,8 \\
\hline K-type expansive agent & 1,7 & 12,1 & 0,5 & 1,2 & 27 & 55,4 & 15,6 & 71 & 1,6 & 0,5 \\
\hline
\end{tabular}

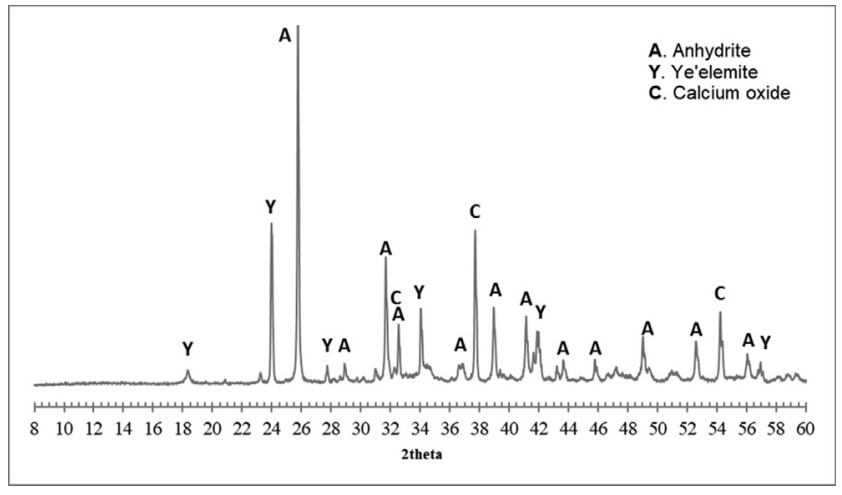

Fig. 1. XRD of K-type expansive agent used.

the water was added the mixture was mixed during 3 additional minutes.

\subsection{Test procedures}

\subsubsection{Basic concrete properties}

The basic properties in the fresh state (slump, V-funnel time, air content and density) and hardened state (expansion rate and compression strength at 7 and 28 days) were determined, as well as the mineralogical composition of the mixtures at different ages, in order to assess the influence of the K-type expansive agent contents on these properties.

Slump and V-funnel time were tested according to EN 12350-8 [28] and EN 12350-9 [29]. Density and air content were determined according to EN 12350-6 [30] and EN 12350-7 [31].

In the hardened state, compressive strength was evaluated on cylindrical specimens of $\emptyset 150 \mathrm{~mm} \times 300 \mathrm{~mm}$ size at the ages of 7 and 28 days, fabricated and cured (T: $20 \pm 2{ }^{\circ} \mathrm{C}$; HR $\geq 95 \%$ ) according to EN 12390-3 [32]. Two specimens were tested for each age and concrete mix. The equipment used was a Compression test machine IBERTEST MEH-3000-W class 1 according to EN 12390-4 [33].

The determination of the mineralogical composition of the raw materials and the evolution of the crystalline phases of the mixes was carried out at the hydration ages of 1, 3 and 7 days by X-ray diffraction analyses (XRD), using a Bruker ADVANCE D8 diffraction equipment whose X-ray tube is a $2.2 \mathrm{~kW}$ copper anode, working in Bragg-Brentano geometry with a 20 -range of $5^{\circ}-60^{\circ}$ at a pitch velocity of $2,37^{\circ} / \mathrm{min}$. The analyses were carried out on powder samples obtained by crushing, with a maximum particle size under $80 \mu \mathrm{m}$.

For all samples, the hydration process was stopped at the desired curing age by removing the free water with isopropanol, acetone and diethyl ether.

\subsubsection{Expansive properties}

Concretes that incorporate K-type expansive agent based on calcium sulfoaluminate show an expansive behavior that depends, among other factors, on the added dose, the degree of restriction and the curing conditions [34]. In this research, three curing environments were considered, named $\mathrm{C} 1, \mathrm{C} 2$ and $\mathrm{C} 3$ (Table 3):
- Curing C1 reproduces the environment considered most favourable for the expansion to occur during the first 7 days by placing the specimens in a water-saturated atmosphere, since the continuous supply of water in this environment favours the hydration of the related expansive compounds.

- Curing C2 simulates the most likely environment for the concrete that fills the gap between the reinforced columns and the prefabricated jacketing, where the concrete has neither significant gains nor losses of water, by wrapping the specimens in an impermeable film. In this environment, the hydration of the expansive compound is carried out with the own concrete mixing water, without additional water supply to produce the phenomena of expansion [35-37].

- Curing C3 simulates the expected conditions around the upper end of the reinforcement system, where the surface of the concrete is exposed to the outside environment, by placing the specimens in a dry chamber. In this case, the loss of mixing water to the environment is favoured, which would hinder the hydration of the expansive compound and could avoid reaching a sufficient magnitude of expansion to guarantee the transmission of tensions to the outer shell. This last curing condition was only applied to double ring device to simulate the drying environment in edge of the reinforcement shell.

The expansion of the designed SCCs must meet a series of requirements taking into account the application to which they are intended (pre-stressing a prefabricated jacket). For this reason, in this research the rate and magnitude of the expansion were evaluated by means of two methodologies:

A standard method based on ASTM C157 and ASTM C878 [38] tests, where the length changes that take place along the longitudinal axis on concrete prism specimens of $256 \times 76 \times 76 \mathrm{~mm}$ are measured in free and restrained condition, respectively. The longitudinal expansion was measured using a digital length comparator with $0,002 \mathrm{~mm}$ accuracy. All specimens were cured during the first $24 \mathrm{~h}$ in a chamber at $20 \pm 2{ }^{\circ} \mathrm{C}$ and relative humidity above $95 \%$. After that time, half of the specimens were subjected to curing $\mathrm{C} 1$, and the other half to curing $\mathrm{C} 2$. Length changes were measured daily until day 14 , and later weekly until day 28.

These standard methods based on prism present the problem that it is necessary to know exactly the setting time for demolding at this time and taking the first reference measurement. This is possible to do under controlled conditions but in cast in place conditions can be very difficult because the rate of the setting time of our mixture can be influenced by the meteorology changes especially temperature changes that can accelerate or decelerate the setting time. To avoid the dependence of the setting time when taking the reference measurement and to know exactly the magnitude of the expansion the following alternative test procedure is proposed in this research.

A method designed ad hoc that simulates, at laboratory scale, the confinement of a cylindrical column by means of a prefabricated outer jacketing filled with concrete. The device consists of two concentric rings (Fig. 2) arranged on a flat non-absorbent 
Table 3

Curing environments for prism ( $\mathrm{C} 1, \mathrm{C} 2)$ and double ring specimens $(\mathrm{C} 1, \mathrm{C} 2, \mathrm{C} 3)$.

\begin{tabular}{|c|c|c|c|c|c|c|c|}
\hline \multirow[t]{2}{*}{ Curing environment reference } & \multirow[t]{2}{*}{ Operation after casting } & \multicolumn{3}{|c|}{ Curing conditions for all specimens } & \multicolumn{3}{|c|}{ Curing conditions for prisms } \\
\hline & & $\begin{array}{l}\text { Time } \\
\text { (days) }\end{array}$ & $\begin{array}{l}\text { Temperature } \\
\left({ }^{\circ} \mathrm{C}\right)\end{array}$ & $\begin{array}{l}\text { Relative } \\
\text { humidity (\%) }\end{array}$ & $\begin{array}{l}\text { Time } \\
\text { (days) }\end{array}$ & $\begin{array}{l}\text { Temperature } \\
\left({ }^{\circ} \mathrm{C}\right)\end{array}$ & $\begin{array}{l}\text { Relative } \\
\text { humidity (\%) }\end{array}$ \\
\hline C1 (initial wet curing) & none & $\begin{array}{l}\text { First } \\
7 \text { days }\end{array}$ & $20 \pm 2$ & $>95$ & $\begin{array}{l}\text { until } \\
28 \text { days }\end{array}$ & $20 \pm 2$ & $50 \pm 5$ \\
\hline C2 (no water exchange) & $\begin{array}{l}\text { wrapped with } \\
\text { retractable film }\end{array}$ & $\begin{array}{l}\text { First } \\
7 \text { days }\end{array}$ & $20 \pm 2$ & $50 \pm 5$ & $\begin{array}{l}\text { until } \\
28 \text { days }\end{array}$ & $20 \pm 2$ & $50 \pm 5$ \\
\hline $\begin{array}{l}\text { C3 (drying on edge of the } \\
\text { reinforcement shell) }\end{array}$ & none & $\begin{array}{l}\text { First } \\
7 \text { days }\end{array}$ & $20 \pm 2$ & $50 \pm 5$ & $\begin{array}{l}\text { until } \\
28 \text { days }\end{array}$ & $20 \pm 2$ & $50 \pm 5$ \\
\hline
\end{tabular}

steel surface with bolts to maintain the equidistance. The inner ring, which simulates the reinforced concrete column, is manufactured in steel with enough thickness to provide it with a rigidity that prevents its deformation. The outer ring, which simulates the external reinforcing jacket, is interchangeable and for this research was manufactured in two of the most used materials for confinement of columns, CFRP and steel. The free space between the rings is filled with the expansive mixtures and the induced expansion is measured by strain gauges placed at $120^{\circ}$ on the inner and outer walls of the device. Three rings for each SCC expansive mixes (SCC-10 and SCC-15), type of outer jacket material (steel and CFRP) and curing conditions $(\mathrm{C} 1, \mathrm{C} 2$ and $\mathrm{C} 3$ ) were tested and the expansion was evaluated during 7 days.

\subsubsection{Experimental validation of the proposed strengthening solution on concrete cylinders}

In order to evaluate the efficiency of the proposed strengthening solution, 6 plain concrete cylindrical specimens $\varnothing 150$ $\mathrm{mm} \times 300 \mathrm{~mm}$ and 8 reinforced concrete cylindrical columns $\emptyset 240 \mathrm{~mm} \times 900 \mathrm{~mm}$ were fabricated and tested at compression, after applying two reinforcement solutions: confinement by CFRP glued directly to the specimens with an epoxy resin (CFRP-D) and confinement based on outer prefabricated CFRP jackets and an expansive SCC filling (CFRP-Ex).

Concrete specimens were casted according to EN 12390-2 [39] capped and tested according to EN 12390-3 in an IBERTEST compression testing machine of $3000 \mathrm{kN}$ capacity. Concrete columns were capped and tested according to EN 12390-3 in an ICON compression testing machine of 1000 Tons. In both cases, only the capped surface of the original concrete elements where in contact with the testing machine steel plates.

Both strengthening solutions, to plain concrete cylindrical specimens and reinforced columns, were compared. In this phase, the expansion induced by the expansive SCC filling was measured by
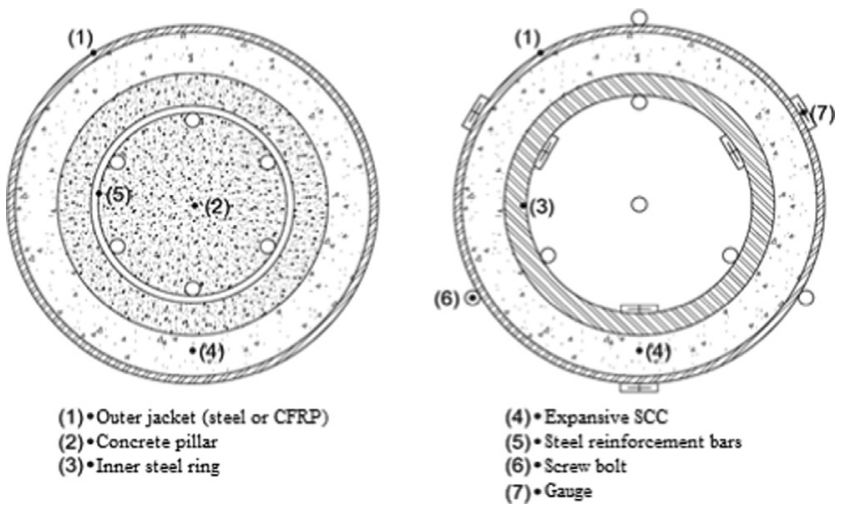

Fig. 2. Scheme of elements that configure the reinforcement system by external jacketing and the arrangement of the double-ring test device designed. strain gauges placed on the prefabricated CFRP jacket at three heights and at $120^{\circ}$ (Fig. 3).

Since the concrete in the cylinders is a porous material capable of absorbing some water, the concrete elements were moistened (specimens by immersion and columns by irrigation- Fig. 4) during the $24 \mathrm{~h}$ prior to filling with the expansive SCC to avoid the loss of water of the filling mixture.

\section{Results and discussion.}

\subsection{Fresh state properties}

The determination of the filling ability, as well as the rest of the fresh properties of the studied SCCs, was carried out during the first 15 min after mixing. Table 4 shows the obtained results.

According to Table 4, the addition of K-type expansive agent, in the proportions of $10 \%$ and $15 \%$, slightly modified the passing ability characteristics of reference concrete SCC- 0 , increasing the slump flow as the added proportion of expansive agent was increased. The slump flow and V-funnel tests did not show signs of segregation in the concrete.

Density of the mixtures decreased slightly as the dosage of type $\mathrm{K}$ expansive agent increased. Air content of the fresh mixtures increased with the increase of the dose of type $\mathrm{K}$ expansive agent with increments of $71 \%$ (SCC-10) and $100 \%$ (SCC-15) with respect to SCC- 0 . This increase in the air content explains the reduction of density observed when the dose of expansive agent was higher.

\subsection{Mechanical properties}

Fig. 5 shows the mean results corresponding to the mechanical tests performed on two concrete specimens per age made from SCC-0, SCC-10 and SCC-15 mixtures.
$\mathbf{A}$

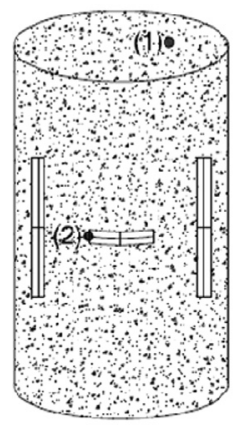
1. Concrete Specimen
2. Strain Gauges
B

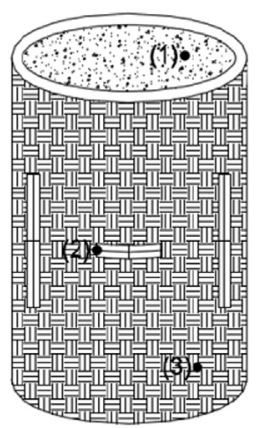

3. CFRP Jacket

4. SCC expansive Filling

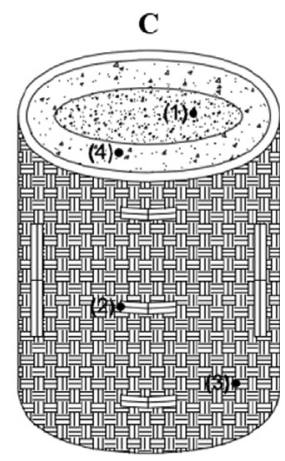

Fig. 3. Strain gauges locations for monitoring expansion for plain concrete (A), CFRP elemens (B) and CFRP + expansive SCC (C) specimens and columns. 

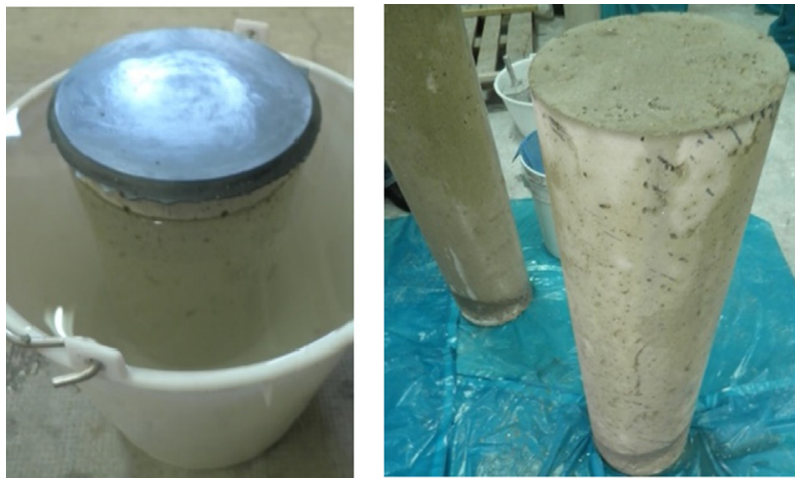

Fig. 4. Moistened specimens-left (immersion) and reinforced concrete columnsright (irrigation)

Other studies and design guides $[40,41]$ show that the compressive strength of shrinkage-compensated concretes is similar or slightly higher than that of a conventional concrete of similar composition cured under the same conditions. However, if the magnitude of the expansion is much greater than that required to compensate the total shrinkage of concrete (self-stressing concrete) and there is no restriction (free expansive regime), the mechanical properties may be negatively affected $[34,42,43]$. The free expansion could induce uncontrolled cracking within the concrete, compromising these properties if the generated cracks are not filled with new hydration products.

This research confirmed those observations. It was observed that the addition of K-type expansive agent in the proportion of $10 \%$ increased the value of compressive strength both at early ages and at the age of 28 days. However, for doses of K-type expansive agent of $15 \%$, the compression strength was lower than the compressive strength of the reference concrete SCC- 0 . Regarding the static elasticity modulus in compression, the SCC-10 mix presented an average value very similar to that of the reference concrete. However, the SCC-15 mix showed a decrease in stiffness of around $20 \%$ with respect to SCC- 0 . This decrease in mechanical properties can be due to two factors: on one hand, the increment in the percentage of air content (Table 4) introduced by the use of expansive agent, and on the other, the likely greater extent of microcracking of the cement matrix because of the larger magnitude of expansion developed in free regime by the SCC-15 mix (see Fig. 7).

\subsection{Mineralogical development of hydration products - X-ray diffraction (XRD)}

XRD analysis focused on the analysis of the evolution of the main anhydrous related to the expansion phenomena (ye'elemite- $\mathrm{C}_{4} \mathrm{~A}_{3} \check{\mathrm{S}}$ ) and of the hydrated calcium sulfoaluminate phases (ettringite- $\mathrm{C}_{6} \mathrm{~A} \check{S}_{3} \mathrm{H}_{32}$ and monosulfate- $\mathrm{C}_{4} \mathrm{~A} \check{S}_{\mathrm{H}} \mathrm{H}_{12}$ ). The analysis was carried out over the diffraction angle interval 5-25 20 on samples at ages of 1, 3 and 7 days (age which was detected the maximum expansion value) that were cured under $\mathrm{C} 1$ and $\mathrm{C} 2$ conditions.

The anhydrous phase ye'elemite- $\mathrm{C}_{4} \mathrm{~A}_{3} \check{S}$ was detected in SCC-10 and SCC-15 mixtures at the angle $23,62 \theta$ at day 1 of hydration.
This peak was not detected in the SCC- 0 mixture since this anhydrous phase is a component of the K-type expansive agent. The ye'elemite content decreased as the hydration age increased in both curing conditions, C1 (with water supply) and C2 (no water exchange). The XRD analysis did not detect ye'elemite from day 3 in SCC-10 (Fig. 6) and from day 7 in SCC-15 (Fig. 7) demonstrating that, even without external water supply, the composition water of the concrete mixtures was enough to carry out the hydration of the anhydrous expansive compound ye'elemite and produce expansions for K-type expansive agent proportions of $10 \%$ and $15 \%$. The consumption of anhydrous ye'elemite seems to be related to the expansive mechanism since as the anhydrous was consumed, the magnitude of the expansion increased. In SCC-15, where the presence of ye'elimite was detected at the age of 7 days according to the XRD analysis, an increase in expansion could be expected depending on the available water (external or internal), amount of anhydrous, degree of restriction imposed and rigidity of the cementitious matrix. However, in the particular restriction and curing conditions of this study, where curing is carried out until the age of 28 days without additional water intake from day 7 , the presence of ye'elimite does not present any additional implication.

XRD analysis detected ettringite in crystalline phase in all samples (SCC-0, SCC-10 and SCC-15) from the initial ages of hydration. The ettringite content estimation was determined from the relative intensity value of the three main peaks of the hydrate from the XRD diffractograms. Ettringite content in the mixtures with expansive agent were higher than in the reference concrete. This result is logical since the presence of ettringite was favored by the incorporation of the K-type expansive agent.

Figs. 8 and 9 show a graphs comparing the ettringite content estimated from the relative intensity measurements of the samples with $0 \%, 10 \%$ and $15 \%$ of K-type expansive agent (columns) and the degree of expansion developed during the first seven days under the curing conditions C1 and C2 (lines). In Fig. 8, the expansion was determined on prisms in free regime according to ASTM C157 and in Fig. 9 was determined on restrained prisms according to ASTM C878. Mixtures with K-type expansive agent (SCC-10 and SCC-15) showed an ettringite content higher than mixture SCC-0, this fact is logical because the K-type expansive agent boost the formation of ettringite. However, comparing SCC-10 and SCC-15 mixtures, both presented a very similar estimated ettringite content, although the amount of expansion in the free and restrained regimes of the SCC-15 was at least one order of magnitude higher in both curing conditions. Therefore, it is unlikely that the conventional crystalline ettringite, identifiable and semi-quantifiable by $\mathrm{XRD}$, is the main mechanism responsible of the expansion in $\mathrm{K}-$ type expansive agent. This result is supported by other findings of the authors [34] where de expansion mechanism seems to be related to an amorphous kind of ettringite non XRD detectable.

\subsection{Expansion regimes: Influence of the curing conditions}

\subsubsection{Free and restrained linear expansion in prismatic specimens,} standard tests

The longitudinal expansion of the fabricated concretes with and without restriction was evaluated by means of the ASTM C157 and

Table 4

Characteristics measured in the fresh state in the fabricated concretes.

\begin{tabular}{|c|c|c|c|c|}
\hline Concrete & Slump flow- $d_{f}(\mathrm{~mm})$ & V-funnel $T v(\mathrm{~s})$ & Density $\left(\mathrm{kg} / \mathrm{m}^{3}\right)$ & Air content (\%) \\
\hline SCC-0 & 700 & 3,0 & 2217,8 & 5,1 \\
\hline SCC -10 & 705 & 2,9 & 2168,3 & 8,7 \\
\hline SCC -15 & 708 & 3,2 & 2149,4 & 10,2 \\
\hline
\end{tabular}



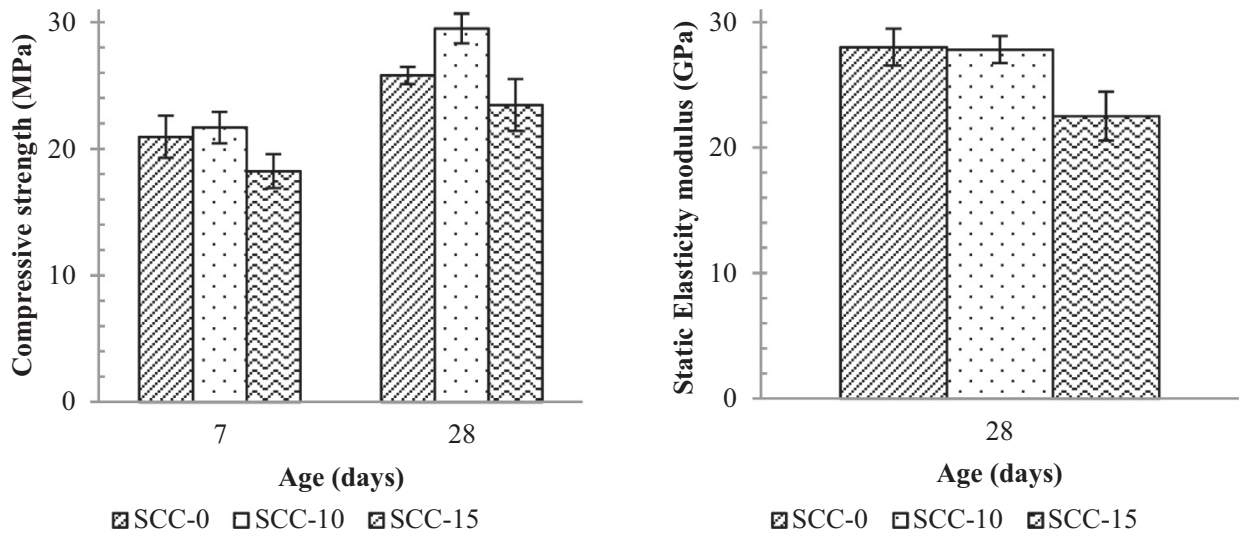

Fig. 5. Average values of compressive strength at 7 and 28 days (left) and of static elasticity modulus at 28 days (right).

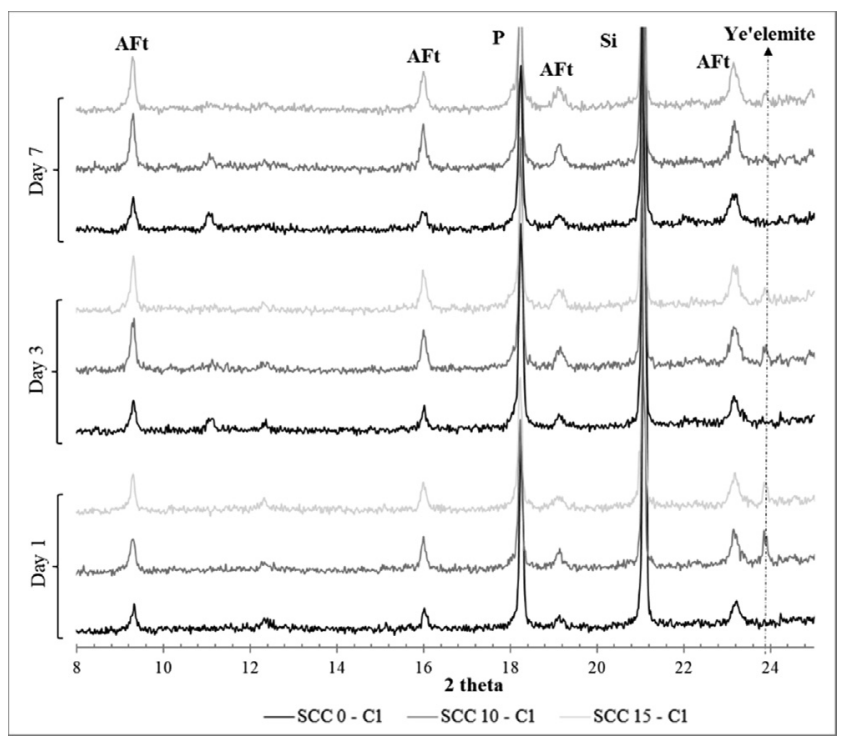

Fig. 6. SCC Diffractograms in C1 curing environment.

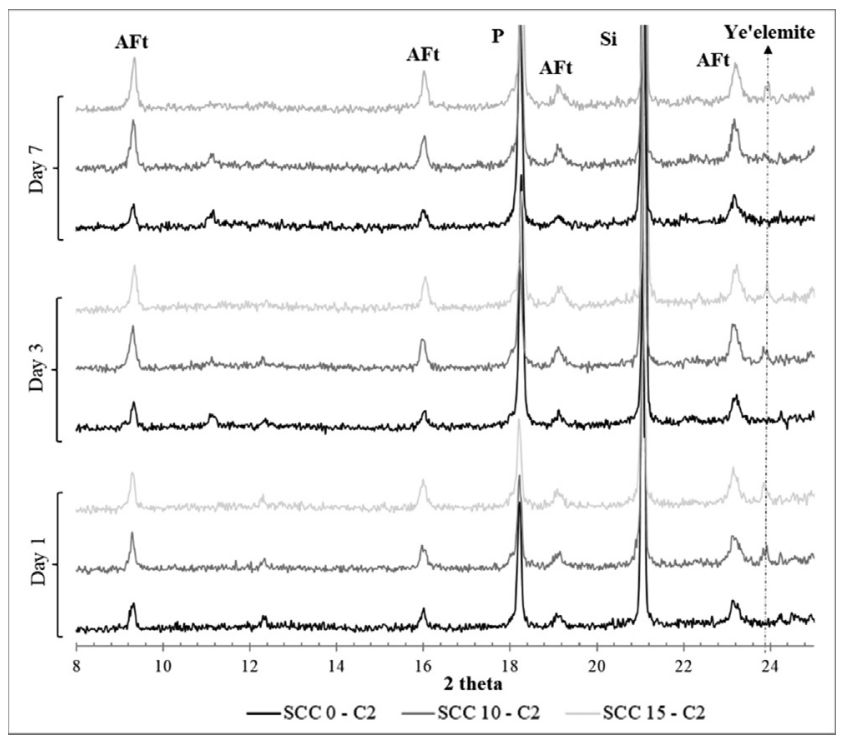

Fig. 7. SCC Diffractograms in C2 curing environment.
ASTM C878 methods under two different curing environments, C1 and C2. Results are shown in Fig. 10.

A higher content of expansive agent increased the magnitude of the expansion developed. The SCC-15 mix is considered the most effective mixture for the purposes of this study, since, for any of the imposed curing and restriction conditions, it develops the largest magnitude of expansion. For the SCC-15 mix, a considerable amount of expansion remains after 28 days under both $\mathrm{C} 1$ and C2 curing conditions, while the $10 \%$ dose of expansive agent (SCC-10) barely produces a significative degree of expansion.

The type of curing influences the maximum magnitude of the developed expansion in the prisms. As expected, the continuous supply of water from an external source favors the hydration of the expansive compound, facilitating expansive reactions and the formation of expansive compound. Regardless of the expansive agent dose, specimens cured in $\mathrm{C} 1$ condition with continuous water supply showed greater expansion than those cured in the C2 environment, both in the free and restrained condition.

The results show how the concrete mix water (C2 environment) is enough to hydrate the expansive agent and generate expansions that overcome the initially imposed restriction, compensating the observed shrinkage that starts after 7 days (SCC-10) or resulting in a remaining deformation (SCC-15) after 28 days.

Shrinkage mechanism was manifested when the water supply, internal or external, was stopped. The main contraction volume phenomena that occur for the particular conditions of this research are two: drying and autogenous shrinkage. The predominance of one or the other depends on the curing conditions: in specimens cured under $\mathrm{C} 1$ conditions, the predominant shrinkage phenomena was drying shrinkage, while in the case of the samples subjected to the $\mathrm{C} 2$ curing conditions, where there is neither loss nor gain of water, the predominant phenomena shrinkage was autogenous shrinkage.

The doses of K-type expansive agent used in this study, $10 \%$ and $15 \%$, were enough to overcome the restriction imposed and develop expansion in different curing conditions (wet curing, no water exchange and drying).

\subsubsection{Restrained circumferential expansion}

The circumferential strains induced in outer jackets by the expansion of the filling were determined by mean the doublering device proposed in Section 2.2.2 and showed in Fig. 11.

Fig. 12 shows the expansion curves obtained during the first 7 days with the double-ring device for the SCC- 10 and SCC- 15 mixtures, under three curing conditions (C1, C2 and C3) and two restrictions (CFRP and Steel outer jacket). 

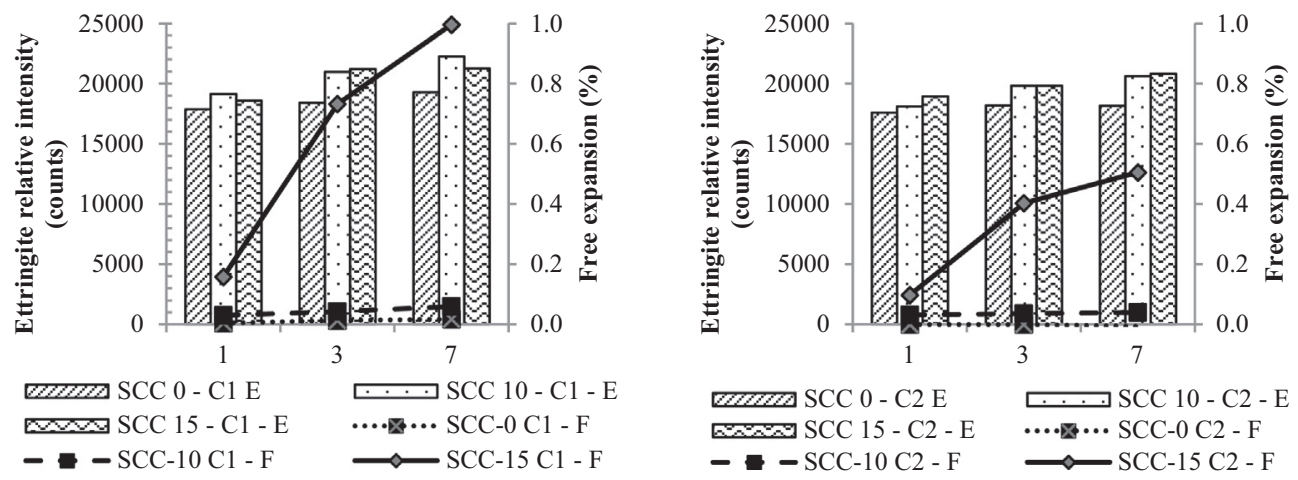

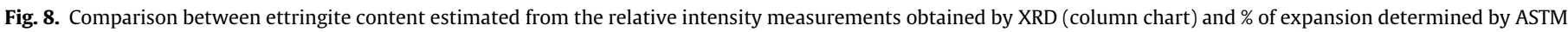
C157 (line black chart) developed in C1 and C2 curing environments.
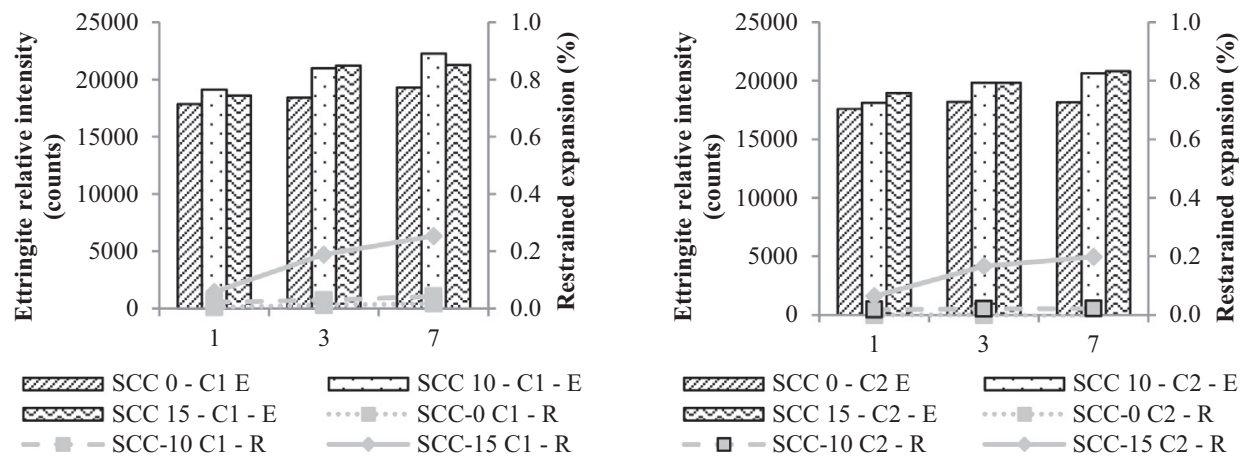

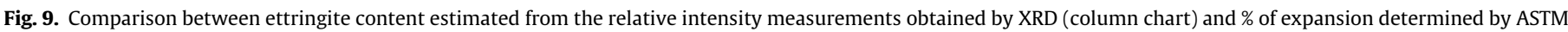
C878 (line grey chart) developed in C1 and C2 curing environments.
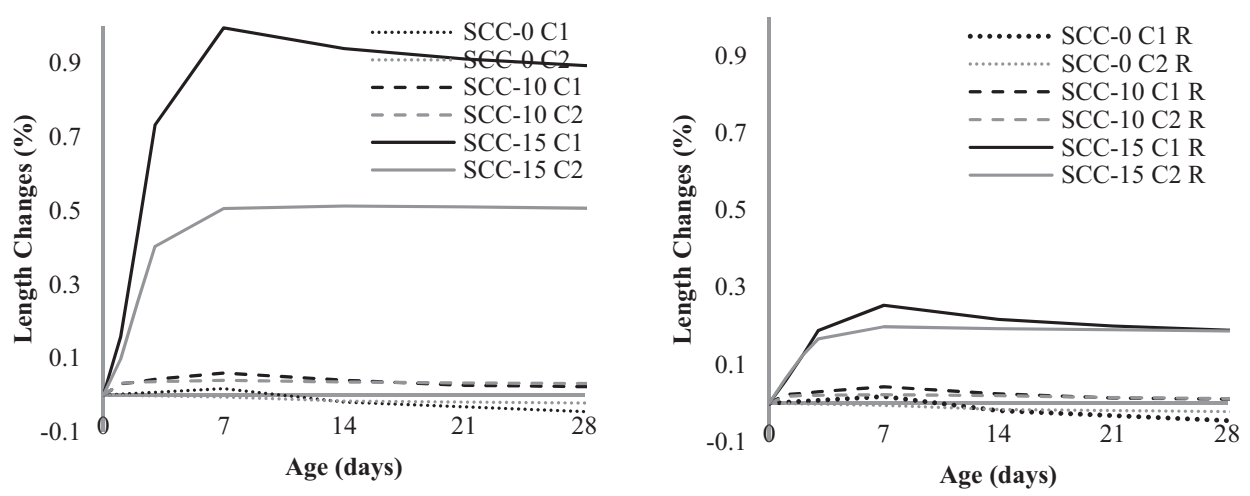

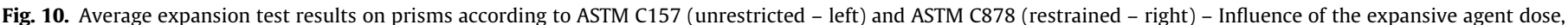
curing environment and restriction on the magnitude of the expansion.

For all cases, the outer jacket (steel or CFRP) went into tension due to the expansive action of the expansive SCCs. The magnitude of the expansion varied depending on the dose of expansive agent, environment and imposed restriction. Strains measured on the inner ring were negligible, which indicates that the inner ring was rigid enough to simulate effectively the effect of a solid column.

The initial development of the expansion, represented by the slope of the curves in the first $24 \mathrm{~h}$, was very similar (the curves overlap) for the doses studied, the two restriction conditions imposed and the three environmental conditions. This observation suggests that the initial development of the expansion is mainly carried out by using only the concrete composition water, without the need for external water supply.
The $\mathrm{C} 1$ environment (wet curing) presented the largest degree of expansion compared to the rest of the curing conditions, all other conditions being equal. This is due to the external and continuous contribution of water that favors the hydration of the expansive agent and the formation of ettringite, which facilitates the development of expansive reactions. In this environment, the curve of expansion presents two well-differentiated sections, one of initial steep slope related to a rapid initial development of the expansion and another subsequent corresponding with a more progressive evolution of the expansion. These two branches match with the already observed behavior on prisms, described in Section 3.4.1.

For the C2 curing conditions (no water exchange), the development of the expansion is more progressive than for the $\mathrm{C} 1$ environ- 


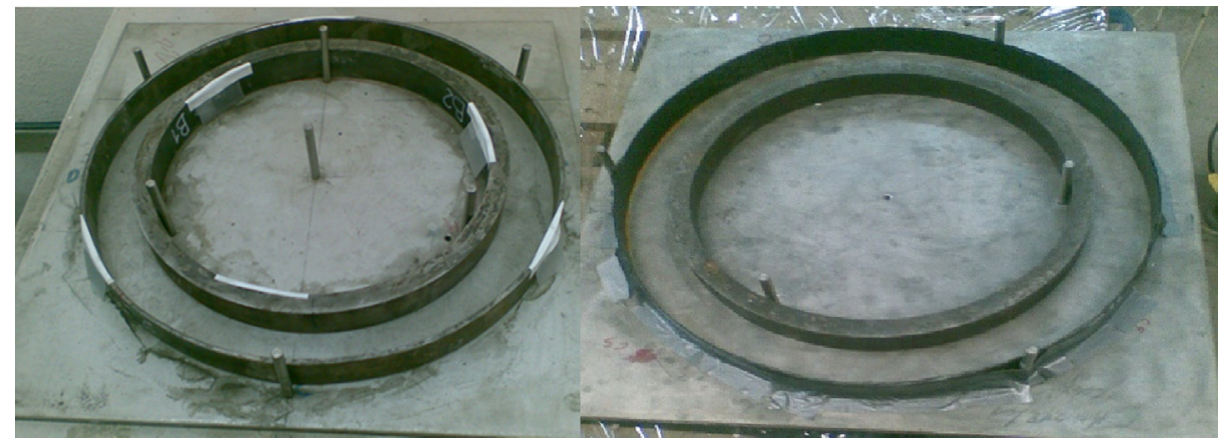

Fig. 11. Double-ring test device with outer steel jacket (left) and CFRP jacket (right).-
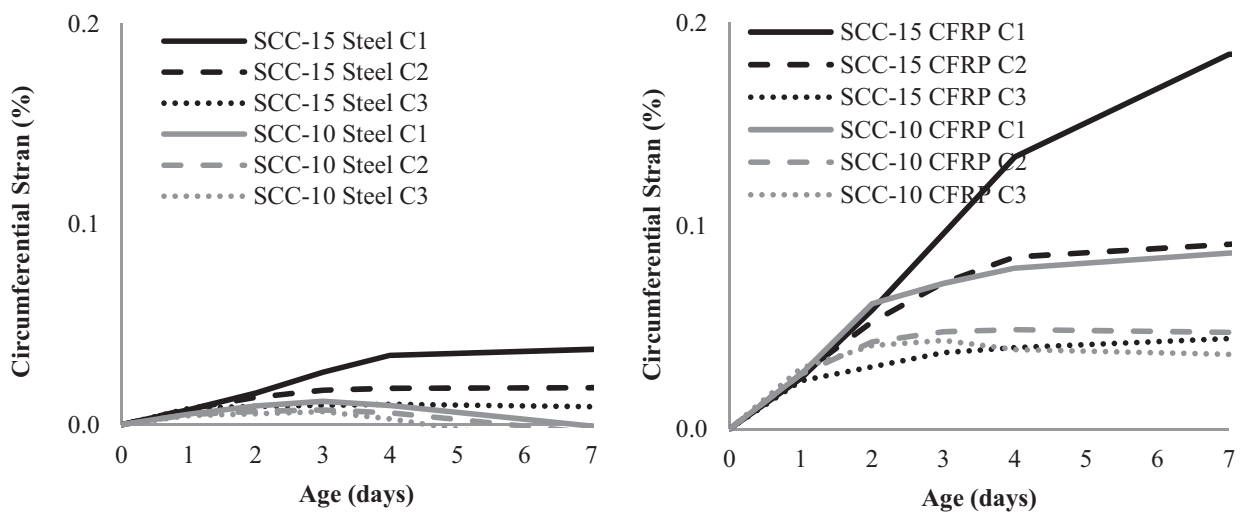

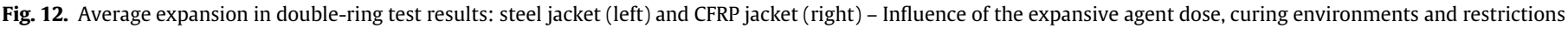
on the recorded expansion.

ment, since there is less water available for the expansive reactions to take place. For the SCC-10 mix, a slope change took place in the expansion curve between days 1 and 2, and between days 3 and 4 for the SCC-15 mix. For SCC-15, the maximum expansion reached in the steel ring in environment $\mathrm{C} 2$ is $48.4 \%$ lower than the expansion recorded for $\mathrm{C} 1$, and $49.8 \%$ lower in the CFRP ring. For the SCC$10 \mathrm{mix}$, the maximum expansions are $63.4 \%$ and $54.5 \%$ lower for the steel and CFRP rings, respectively. In spite of the reduction in the expansion capacity, results are very satisfactory because they showed that, in $\mathrm{C} 2$ environment (the most likely conditions in the filling of the proposed confinement system), the internal water supply of the expansive SCC is enough to ensure that expansion takes place and pre-loads the outer reinforcement jacket.

In the $\mathrm{C} 3$ environment (drying), the initial development of the expansion during the first $24 \mathrm{~h}$ is the same as the rest of the environments for all cases. However, the subsequent development of the expansion stopped once the available internal water was consumed, and it is not possible to continue with the hydration of the expansive agent. For this reason, in this environment, the magnitude of the expansions recorded was the lowest. Even so, observing that the expansions take place during the first hours even while the concrete loses water ensures that the entire jacket is initially tensioned, avoiding possible loss of contact between the filling concrete, the column and the reinforcement jacket. In addition, the small size of the area of filling material in possible contact with a dry environment suggests that this phenomenon will not be very relevant for the entire reinforcement system, ensuring its effectiveness.

Therefore, in the curing conditions studied, the double-ring test device registered the expansions effectively, simulating the reinforcement configuration in columns based on confinement by prefabricated outer CFRP or steel jacketing and filling expansive SCCs. Besides, this device presents advantages respect to the ASTM C878 standard test, since it allows to record the expansion strains from the very first moment that the concrete is casted, avoiding depending on the setting time, and to determine the development of expansion under different restriction conditions.

3.4.3. Correlation between the expansion measurements on restrained prisms according to ASTM C878 and on the double-ring device

Based on previous results, the mixture SCC-15 fulfilled the objective of obtaining a self-stressing SCC for its use as a filling in a confinement system with outer prefabricated jackets.

The expansion measurements obtained during the first 7 days using the SCC-15 mixture on restrained concrete prisms and on steel and CFRP rings subjected to the same curing environments were compared. Results showed that the relationship between the strains determined on the double-ring device with steel or CFRP reinforcement jacketing and those registered on prismatic specimens according to ASTM C878 are linear, with a very high coefficient of determination $\mathrm{R}^{2}$ (Fig. 13).

This good correlation between the proposed method and the standard prisms would allow the possibility of proposing a design procedure for expansive concrete intended for the filling of column confinement systems similar to that included in the American Concrete Institute Guide for shrinkage compensating concrete ACI 223 established by Russel [44], updating the design abacuses to the measurements made with the double-ring device proposed in this study.

\subsection{Experimental validation on reinforced concrete cylinders}

\subsubsection{Degree of expansion in cylindrical concrete specimens and} reinforced concrete columns

Measurements of the circumferential strains in cylindrical specimens $\varnothing 150 \mathrm{~mm} \times 300 \mathrm{~mm}$, subjected to C2 curing conditions, 


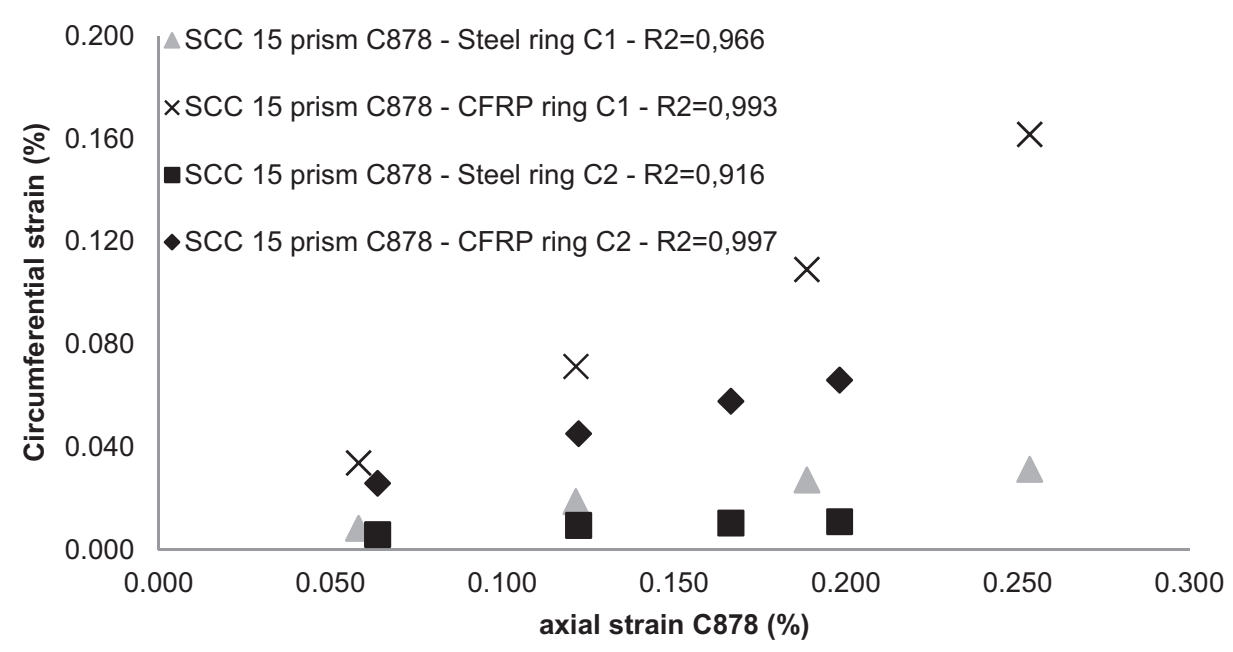

Fig. 13. Relationship between the results obtained in prisms according to C878 and the double-ring test device during the first 7 days.

with an outer CFRP prefabricated jacketing and an expansive SCC filling, allowed to verify that the expansion regime induced by the SCC-15 mixture on the jacketing was very similar to that recorded in the double ring test device with the same material, mixture and curing (Fig. 14).

In cylindrical reinforced concrete columns, it was observed that two columns (numbered 1 and 3) presented expansion curves similar to the ones obtained on cylindrical specimens and the doublering device (Fig. 14), with a maximum average value of expansion of $0.086 \%$. However, the other two columns ( 2 and 4 ), reached a maximum average expansion value of $0.051 \%, 59 \%$ lower than the expansion registered in the first pair of columns.

The reason of this reduction in the magnitude of the expansion in column elements 2 and 4 may be due to poor wetting by irrigation on those columns (note the differences in coloration between both columns in Fig. 4 on the right). Thus, part of the composition water of the filling concrete may have been absorbed by the porous surface of the support, since it was not completely saturated, limiting the hydration of the expansive agent and therefore the expansion. This study has shown already in previous tests that the available water of the SCC mixture influences the development of the expansion and its maximum value. Thus, the complete wetting of the support must be guaranteed to prevent the porous surface of the concrete from absorbing part of the composition water of the expansive SCC filling mixture. Even so, the average value of expan-

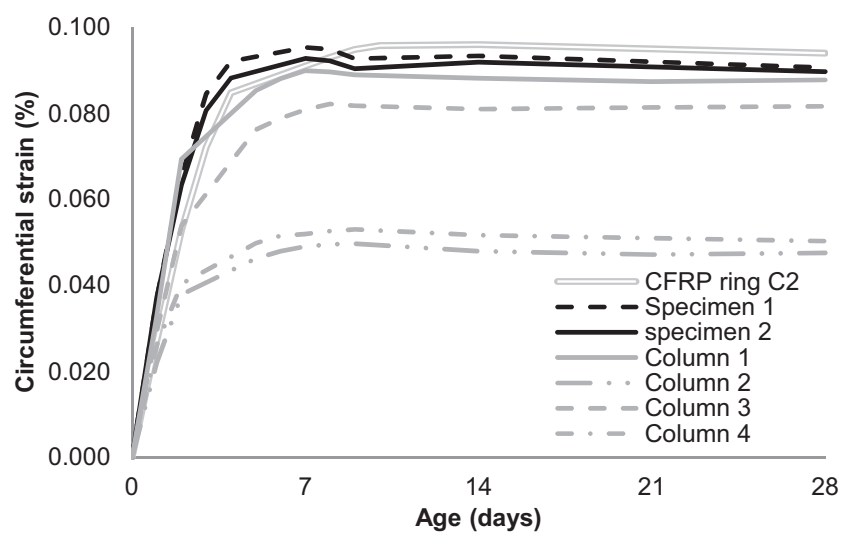

Fig. 14. Individual expansion regime comparison between the double-ring test, cylindrical specimens and columns, all of them fabricated with the SCC-15 mix, with a CFRP jacketing and under curing environment $\mathrm{C} 2$. sion on columns 2 and $4(0.051 \%)$ is considered enough to pre-load the external jacketing as intended.

3.5.2. Mechanical contribution of the proposed strengthening system to cylindrical specimens and reinforced concrete columns

The two strengthening techniques applied, confinement by CFRP glued directly to the columns with an epoxy resin and confinement based on outer prefabricated CFRP jacketing and an expansive SCC filling, increased the capacity to withstand compressive loads with respect to the plain concrete elements. The increase of the strength capacity in specimen type elements was very similar for the two reinforcement conditions, with increases of $173 \%$ for the directly glued CFRP reinforcement and of $187 \%$ for the filled jacketing (Fig. 15). However, in the reinforced concrete columns, the proposed reinforcement solutions showed considerable differences among them, obtaining with the filled CFRP jacketing solution a greater load capacity than the glued CFRP reinforcement. These differences, however, cannot be attributed solely to the differences between the reinforcement systems, but are attributed, in part, to the effect derived from buckling of the internal bar reinforcement within the columns, as it is discussed later.

3.5.2.1. Stress-strain response. Fig. 16 shows the stress-strain curves obtained from the compression tests on the concrete specimens and columns. The results allow to verify that the initial confine-

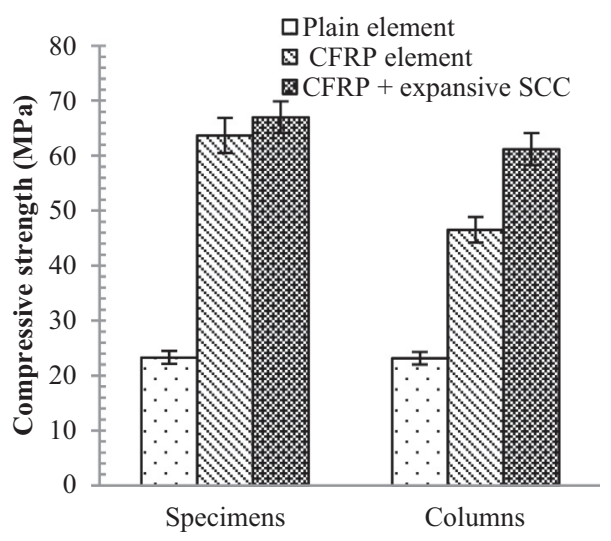

Type of element tested

Fig. 15. Average compression strength obtained on cylindrical specimens and reinforced concrete columns - Contribution of the strengthening systems. 
ment action exerted by the CFRP directly glued (CFRP-D) on the concrete elements was passive, i.e. the reinforcement is not effective until a certain overload and strain level were reached. The stress-strain curves of this strengthening system present a bilinear response with two well-differentiated slopes. The first branch of the curves has a slope that is almost coincident with the slope of the unreinforced plain elements. Thus, the stiffness in this part of the curve is attributed to the contribution of the rigidity of the column itself, and it indicates that the confinement action of the glued CFRP did not work at this point because the circumferential strains in the concrete column due to the applied axial load were not enough to put on tension the CFRP jacketing.

After this initial slope, once the concrete element has reached a certain level of strain the CFRP jackets begins to act passing to be from passive to active reinforcement. At this point the stressstrain curve presents a much flatter slope where for a small increments of load produce higher circumferential strains.

On the other hand, the proposed reinforcing solution for confinement by means of prefabricated external jackets of CFRP and filling SCC-15 (CFRP-Ex) transforms the passive strengthening system based on CFRP glued to the column into an active one. The prestressing effect is evident in the stress-strain curves (Fig. 16), which have a steeper initial slope in both case, specimens and columns, than those determined in non-reinforced elements or those with direct reinforcement of CFRP, meaning that the CFRP jacket and the concrete element work together showing a greater capacity of load for equal deformation of the outer jacket. This change in reinforcement behavior is due to the filling SCC-15 expansive action that develop a tensile stress of the CFRP outer jacket from the initial moment of its application, not being necessary any additional strain in the reinforced concrete element to put into work the strengthening applied.

3.5.2.2. Failure modes. Figs. 17 and 18 illustrate the failure modes of the cylindrical concrete elements tested, both without reinforcement and with the two alternatives of confinement contemplated.

All elements tested with CFRP reinforcement, direct or indirect, fail because of the CFRP jacket breaks due to the circumferential tension. The failure occurs in a sudden and explosive way, preceded by a series of sounds before breaking.

The zone in which the failure is located varies depending on whether it was a specimen or reinforced concrete columns, depending on the area of stress concentration and reinforcement type. In specimen elements, where the effect of both active
(A)

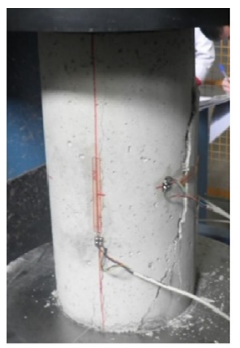

(B)
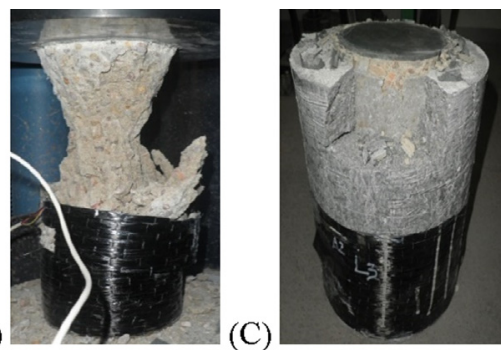

Fig. 17. Failure modes registered in specimens. Concrete without reinforcement (A), direct reinforcement of CFRP (B), prefabricated CFRP jacket + SCC-15 (C).
(D)

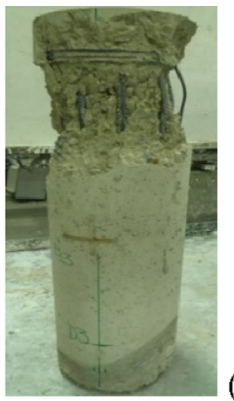

(E)

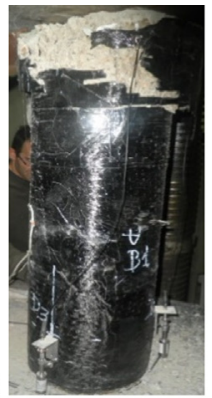

(F)

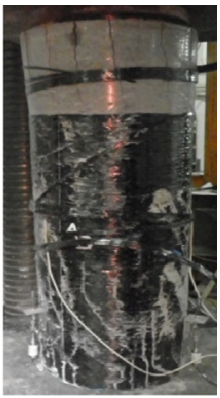

Fig. 18. Failure modes registered in reinforced columns. Concrete without reinforcement (D), direct reinforcement of CFRP (E), prefabricated CFRP jacket + SCC-15 (F).

(CFRP-Ex) and passive (CFRP-D) confinement is more effective, (see Fig. 16), the failure due to breakage of the CFRP jacketing is located in the central third of the height of the specimen (Fig. 17). However, in column elements with corrugated steel bars reinforcing, the zone of failure moves towards the upper quarter of the columns. This failure mode is produced because the local buckling of the internal reinforcement generates a concentration of stresses in the zone near to the head of the columns (Fig. 18), diminishing, in this way the effectiveness of the confinement provided by the both CFRP jacketing solutions applied.

In any case, the observed behavior makes it possible to confirm that the proposed strengthening solution based on prefabricated CFRP jackets and filling SCC-15 is more effective than the usual one used based on CFRP jackets directly glued to the columns.
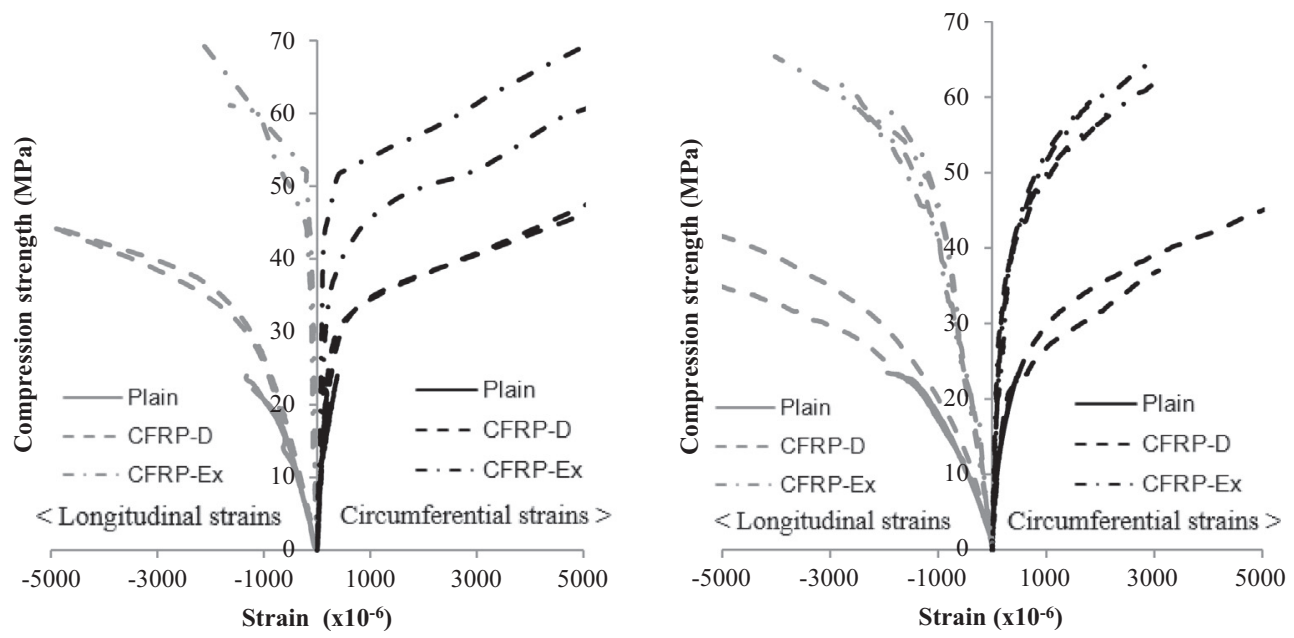

Fig. 16. Stress-strain curves of plain, CFRP directly glued (CFRP-D), and CFRP + SCC-15 filling (CFRP-Ex) in specimens (left) and columns (right). 


\section{Conclusions}

This research shows that:

It is possible to obtain an active system for the reinforcement, retrofitting or repairing of concrete columns, consisting of a rigid prefabricated outer jacketing of steel or carbon-fibre reinforced polymer, plus a filling of an expansive self-compacting concrete that, when it expands, pre-stresses the jacketing from the first days since its installation.

The addition of a K-type expansive agent in the proportions of $10 \%$ and $15 \%$ maintained the self-compacting condition of a reference self-compacting concrete intended as filling, although there was a slight increase in slump flow, flow time and air content when the K-type expansive agent dose was increased.

The addition of the expansive agent modified the mechanical properties of the reference SCC mix. For free expansion (unrestricted), a $10 \%$ of expansive agent increased the compressive strength value. However, increasing this dose up to $15 \%$ translated into a loss of compressive strength and modulus of elasticity.

The expansion mechanism on K-type agent is directly linked to the consumption of the anhydrous compound ye'elemite, but not to the increase in ettringite detectable by X-ray diffraction, since for similar estimated contents of ettringite detected by XRD, the expansion values differed in almost one order of magnitude on specimens with different expansive agent doses (10\% and $15 \%$ in this case).

The dose of K-type expansive agent, the restriction type and the curing environment conditioned the development of the expansion.

The compositional mix water of the concrete, in an environment without water exchange, is enough to hydrate the expansive agent and to induce the expansions that overcome the imposed restriction, guaranteeing the shrinkage compensation (10\% dose) or a permanent chemical pre-stressing effect (15\% dose).

The double-ring test device showed a high degree of correlation to the standard ASTM C878 test on prisms, under different curing environments and restriction conditions. Besides, allowed record the expansion strains effectively from the very first moment that the concrete is casted without depending on the setting time.

The proposed active reinforcement solution of a CFRP prefabricated outer jacketing and the use of an expansive SCC filling improves the mechanical response of a concrete cylindrical elements, increasing the compressive strength and stiffness of the original elements by providing an uniform confinement effect over their entire length from casting.

The conditioning operations of the concrete element to be reinforced, prior to the application of the proposed confinement solution, are essential to avoid any alteration of the SCC filling mixture to fulfill the expected mechanical and expansion behaviour.

\section{Declaration of Competing Interest}

The authors declare that they have no known competing financial interests or personal relationships that could have appeared to influence the work reported in this paper.

\section{Acknowledgements}

Authors gratefully acknowledge the Spanish Ministry of Economy and Competitiveness for the financial support given to this research in BIA2015-64363-R project. They are grateful to IMCD España Especialidades Químicas, S.A. for supply the expansive agent used in this study.

\section{References}

[1] Khair Al-Deen Isam Bsisu, "Retrofitting of Square Reinforced Concrete Columns Subjected to Concentric Axial Loading with Steel Jackets" C.E.O. Al-Eman Housing Company.

[2] The international federation for structural concrete (CEB-FIB), technical report bulletin 14. Externally bonded FRP reinforcement for RC structures, julio 2011, 138 p. ISBN 2-88394-054-1.

[3] Priestley M.J.N., F. Seible., and G.M. Calvi, Seismic Design and Retrofit of Bridges, , New York, John Wiley \& Sons, abril 1996., 704p., ISBN: 978-0-47157998-4.

[4] Yogesh Chhabra, Bridge Rehabilitation Techniques, general manager, the DSbrown company, 57 pioneer road, Singapore 628508, web www. dsbrown.com, 2004.

[5] The international federation for structural concrete (CEB-FIB), technical report bulletin 39, Seismic bridge design and retrofit - structural solutions, state of art report, may 2007, 300 p. ISBN 978-2-88394-079-6.

[6] G.L. Rai, "Different Strengthening Techniques for RC Columns", R\&M International.

[7] ACI Committee 440, ACI 440R-07, Report on Fiber-Reinforced Polymer (FRP) Reinforcement for Concrete Structures, American Concrete Institute, 2007, 100 p.

[8] H. Nasersaeed, Evaluation of behavior and retrofitting RC structures with concretes jacktes, Asian J. Appl. Sci. Malaysia 4 (3) (2011) 211-228.

[9] E. Choi, Y.-S. Chung, J. Park, B.-S. Cho, Behavior of reinforced concrete columns confined by new steel-jacketing method, ACI Struct. J. 107-s64 (2010) 655662.

[10] Filipe Ribeiro, José Sena-Cruz, Fernando G. Branco, Eduardo Júlio, Hybrid FRP jacketing for enhanced confinement of circular concrete columns in compression, Construction and Building Materials, Volume 184, 2018, Pages 681-704, ISSN 0950-0618, https://doi.org/10.1016/j.conbuildmat.2018.06.229.

[11] J.C.M. Ho, C.X. Dong, Improving strength, stiffness and ductility of CFDST columns by external confinement, Thin-Walled Structures, Volume 75, 2014, Pages 18-29, ISSN 0263-8231, https://doi.org/10.1016/j.tws.2013.10.009.

[12] M.V. Chitawadagi, M.C. Narasimhana, S.M. Kulkarni, Axial strength of circular concrete-filled steel tube columns DOE approach, J. Constr. Steel Res. 66 (2010) 1248-1260.

[13] Bao-chun Chen, You-jie Chen, Ze-bao Qin, Hiroshi Hikosaka, Application of concrete filled steel tubular arch bridges and study on ultimate load-carrying capacity, Arch Bridges ARCH́04 P. Roca and E. Oñate (Eds) CIMNE, Barcelona, 2004.

[14] Walter Luiz Andrade de Oliveira, Silvana De Nardin, Ana Lúcia H. de Cresce El Debs, Mounir Khalil El Debs, Evaluation of passive confinement in CFT columns, Journal of Constructional Steel Research, Volume 66, Issue 4, 2010, Pages 487-495, ISSN 0143-974X, https://doi.org/10.1016/j.jcsr.2009.11.004.

[15] Fernández Luco, L., Fernández, S., Husni, R., Diseño por prestaciones de hormigones de baja retracción para un edificio en altura con grandes dimensiones en planta, en Actas del XIII Congreso Latinoamericano de Patología de la Construcción, CONPAT 2015, (Lisboa, 8 - 10 de septiembre de 2015), comunicación 8444, 2015.

[16] S. Nagataki, H. Gomi, Expansive admixtures (mainly ettringite), Cem. Concr. Compos. 20 (1998) 163-170.

[17] ACI committee 223, ACI 223R-10, Guide for the use of shrinkage Compensating Concrete, American Concrete Institute, 2010, 16p.

[18] Hoff G. C., Expansive Cements And Their Uses, US Army Engineers Waterways Experiment Station, Concrete Laboratory, Vicksburg, Mississippi, October 1972.

[19] W. Kurdowski, Cement and Concrete Chemistry, Springer Netherlands, XII, 699 p. 477 illus, ISBN: 978-94-007-7944-0 , 2014.

[20] A. Klein, Calciumaluminosulfate and expansive cements containing same, US Patent No. 3, 155, 526, 1963, 4 pp.

[21] P. Klieger, N.R. Greening, Utility of Expansive Cement, Proceedings, Fifth International Symposium on the Chemistry of Cement (Tokyo, 1968), Paper IV132, Cement Association of Japan, Tokyo, 1969.

[22] S. Shadravan, C. Ramseyer, T.H.K. Kang, A long term restrained shrinkage study of concrete slabs on ground, Eng. Struct. 102 (2015) 258-265.

[23] V. Corinaldesi, Combined effect of expansive, shrinkage reducing and hydrophobic admixtures for durable self-compacting concrete, Constr. Build. Mater. 36 (2012) 758-764.

[24] P. Carballosa, J.L. García Calvo, D. Revuelta, J.J. Sánchez, J.P. Gutiérrez, Influence of cement and expansive additive types in the performance of self-stressing and self-compacting concretes for structural elements, Constr. Build. Mater. 93 (2015) 223-229.

[25] J.L. García Calvo, D. Revuelta, P. Carballosa, J.P. Gutiérrez, Comparison between the performance of expansive SCC and expansive conventional concretes in different expansion and curing conditions, Constr. Build. Mater. 136 (2017) $277-285$.

[26] J. Beretka, M. Marroccoli, N. Sherman, G.L. Valenti, The influence of C4A3S content and W/S ratio on the performance of calcium sulfoaluminate-based cements, Cem. Concr. Res. 26 (1996) 1673-1681.

[27] AENOR, Ensayos para determinar las propiedades mecánicas y físicas de los áridos. Parte 6: Determinación de la densidad de partículas y la absorción de agua., UNE-EN 1097-6, Madrid: AENOR, 2014. 
[28] AENOR, Ensayos de Hormigón Fresco. Parte 8: Hormigón Autocompactante. Ensayo del escurrimiento, AENOR, Madrid, 2011.

[29] AENOR, Ensayos de hormigón fresco. Parte 9: Hormigón autocompactante. Ensayo del embudo en V, AENOR, Madrid, 2014

[30] AENOR, Ensayos de hormigón fresco. Parte 6: Determinación de la densidad, AENOR, Madrid, 2009.

[31] AENOR, Ensayos de hormigón fresco. Parte 7: Determinación del contenido de aire. Métodos de presión, AENOR, Madrid, 2010.

[32] AENOR, Ensayos de Hormigón Endurecido. Parte 3: Determinación de la Resistencia A Compresión de Probetas, AENOR, Madrid, 2009.

[33] AENOR, Ensayos de Hormigón Endurecido. Parte 4: Resistencia a Compresión. Características de la máquina de ensayo, AENOR, Madrid, 2001.

[34] P. Carballosa, J. Calvo, D. Revuelta, Influence of expansive calcium sulfoaluminate agent dosage on properties and microstructure of expansive self-compacting concretes, Cem. Concr. Compos. (2020) 107103464.

[35] M. Collepardi, A. Borsoi, S. Collepardi, J.J.O. Olagor, R. Troli, Effects of shrinkage reducing admixture in shrinkage compensating concrete under non-wet curing conditions, Cem. Concr. Res. 27 (2005) 704-708.

[36] M. Collepardi, G. Baldini, M. Pauri, M. Corradi, Tricalcium aluminate hydration in the presence of lime, gypsum or sodium sulfate, Cem. Concr. Res. 8 (5) (1978) 571-580.
[37] P.K. Mehta, F. Hu, Further evidence for expansion of ettringite by water adsorption, J. Am. Ceram. Soc. 61 (3-4) (1978) 179-181.

[38] ASTM C157/C157M-08, Standard Test Method for Length Change of Hardened Hydraulic-Cement Mortar and Concrete, ASTM International, West Conshohocken, PA, 2014.

[39] EN 12390-2, Testing hardened concrete - Part 2: Making and curing specimens for strength tests, European Committee for Standardization CEN, 2009.

[40] ACI committee 223, ACI 223R-10, Guide for the use of shrinkage Compensating Concrete, American Concrete Institute, 2010, 16p.

[41] Japan Society of Civil Engineers, Recommended Practice For Expensive Concrete, Concrete Library, Concrete Library Of JSCE No. 23, June 1994.

[42] V.V. Bertero, Curing effects on expansion and mechanical behavior of expansive cement concrete, ACI J. Proc. 64 (2) (Feb. 1967) 84-96.

[43] V.V. Bertero, M. Polivka, Effect of degree of restraint on mechanical behavior of expansive concrete, Proc. ASTM 64 (1964) 797-815.

[44] Russell, H. G., "Design of Shrinkage-Compensating Concrete Slabs" Klein Symposium on Expansive Cement Concretes, SP-38, Farmington Hills, MI: American Concrete Institute, 1973, pp. 193-226. 